\title{
Comparing transition of care from adolescence to adulthood for patients with congenital urological conditions in Canada and the U.S.
}

\author{
Rosalia Misseri, MD \\ Riley Hospital for Children at IU Health, Indiana University School of Medicine, Indianapolis, IN, United States
}

Cite as: Can Urol Assoc J 2016;10(9-10):311-2. http://dx.doi.org/10.5489/cuaj.4090

See related article on page 306 .

S uccessful transition of care for the adolescents and the continuity of care for adults with congenital urologic conditions (CUC) is dependent on the availability of healthcare professionals to provide expert care. In addition to clinical expertise, the ability of these professionals to provide care quality care hinges upon support at multiple levels, ranging from the division and hospital in which he or she works, to the national level of their specialty's board and ultimately, to the nation's healthcare system. Additional support, such as that afforded by charities and support groups are also important in the development of successful programs and in sustaining them. Given the complexity of delivering such care, many countries, including the U.S. and Canada, continue to struggle with the development of programs to transition the care of patients with complex congenital genitourinary conditions.

The Canadian Pediatric Society (CPS) has provided a mission statement on the transition of care from pediatric to adult practices. Healthcare goals include involvement of the adolescent in the management of the condition, adolescent and family understanding of the condition, understanding of personal potential, completion of adolescent developmental tasks, and attaining self-esteem and self-confidence. ${ }^{1}$ These are quite similar to those put forth by the American Academy of Pediatrics. ${ }^{2}$ The CPS has outlined several strategies to help transition. At teenage visits, they recommend part of the visit occurring without parents to give the patients an opportunity to discuss their problems, ask and answer questions, and advocate for themselves. Educational material dealing with youth issues and youth living with health conditions are provided to patients and the patients are recommended to attend peer-support meetings in person or online. The hospitals arrange family and teen education days to allow teens to meet each other, gather information, and discuss transitioning to the adult system. Finally, a formal acknowledgement of "graduation" in the form of a certificate from the pediatric staff given to the patient marks a rite of passage, while a letter to the patient and family about the new facility and staff can allow the patient and family know what to expect in the adult setting. ${ }^{1}$ Additionally, CPS recommends a multidisciplinary approach integrated into existing specialty clinic settings that provide a stepwise plan of increasing responsibility for self-care. Transition services may include individual counselling, psychoeducational groups, joint transition clinics, educational materials, and online tools. ${ }^{1}$

The specific needs of adults with CUC almost always outweigh those of a child who presents to a pediatric urology clinic with the same congenital disorder. This can be attributed to a "longer history," increasing needs or worsening of the disease process. For example, concerns associated with sexuality and fertility arise, and renal function may worsen. Colleagues within the division may not appreciate longer patient encounters and more tedious and complicated surgeries, given the patient's extensive surgical history. This may be viewed negatively by departmental colleagues, as peers can see more patients over the same period of time and, in turn, generate more income for the group. In addition, each hospital has a different set of rules for adults with congenital conditions. Some will allow adult patients into a pediatric hospital based on circumstance, others strictly forbid it based on age. Some practitioners are limited to treat patients of a specific age group.

In the U.S., federal and state governments help provide health insurance and benefits to adults with disabilities through services like Medicare and Medicaid. ${ }^{3}$ Medicare is a federally funded healthcare insurance typically for legal residents of the U.S. over the age of 65 . Individuals over age 18 who have received Social Security disability benefits or have been diagnosed with end-stage renal disease and been 
on dialysis for three months or have had a kidney transplant may also benefit from this insurance. Medicaid is a social healthcare program that provides free or low-cost health coverage to low-income people, families and children, pregnant women, the elderly, and people with disabilities with resources insufficient to pay for healthcare. The program is funded jointly by state and federal governments. With the passage of the Patient Protection and Affordable Care Act, often referred to as ObamaCare, children can stay on their parents insurance through age 26 and those with preexisting conditions can obtain insurance coverage during open enrollment. ${ }^{4}$

In sharp contrast to the American healthcare system, a group of socialized health insurance plans provides coverage to all Canadian citizens. It is publically funded and administered locally, with guidelines provided by the federal government. This is available to all citizens regardless of medical history or personal income. Private health insurance plans are also available to supplement primary health coverage. While private clinics do exist, they are not legally allowed to provide services covered by the Canada Health Act. In 2001, healthcare expenditures in Canada were $\$ 100$ billion. Approximately $9.5 \%$ of Canada's gross domestic product is spent on healthcare (approximately $14 \%$ in U.S.).
Despite different healthcare systems with common goals, successful transition remains elusive for many young adults with congenital diseases across North America.

Competing interests: The author reports no competing personal or financial interests.

\section{References}

1. Kaufman M. Transition to adult care for youth with special healthcare needs. Posted November 1, 2007; reaffirmed February 1, 2016. Available at http://www.cps.ca/documents/position/transition-youthspecial-needs. Accessed on September 6, 2016.

2. American Academy of Pediatrics; American Academy of Family Physicians; American College of Physicians; Transitions Clinical Report Authoring Group, Cooley WC, Sagerman PJ. Supporting the health care transition from adolescence to adulthood in the medical home. Pediatrics 2011;128:182-200. http://dx.doi. org/10.1542/peds.2011-0969

3. Brault MW (2012). Americans with disabilities: 2010. Household economic studies. Available at http://www.census.gov/prod/2012pubs/p70-131pdf. Accessed March 13, 2016.

4. Public Law: Law 111-148-Patient Protection and Affordable Care Act of 2010. Congressional Record; 2012. Available at https://www.congress.gov/bill/11 1th-congress/house-bill/3590. Accessed September 6, 2016.

Correspondence: Dr. Rosalia Misseri, Riley Hospital for Children at IU Health, Indiana University School of Medicine, Indianapolis, IN, United States; rmisseri@iupui.edu 